\title{
Pena de muerte en Colombia, una medida no tan extrema a la luz del iusnaturalismo*
}

\author{
Félix Antonio Rojas Martínez \\ Recibido: 6 de junio de 2018 -Aprobado: 20 de agosto de 2018
}

\section{Resumen}

Un tema de discusión semejante no es fácil de abordar, ya que se remonta a los orígenes de la civilización misma. Desde el punto de vista jurídico, es un enfrentamiento entre dos principios fundamentales básicos de cualquier sistema normativo occidental, esto es, entre el principio de libertad y el principio de justicia que se encuentran inmersos y omnipresentes en la esencia misma del derecho. Aunque la ciencia jurídica parece ser la encargada de decidir si es justificable quitar la vida de alguien, la discusión profunda involucra campos del conocimiento que van desde la religión hasta las ciencias naturales y alcanza la órbita de otros problemas jurídicos difíciles como el aborto y la eutanasia. No obstante, el análisis que se pretende llevar a cabo en este ensayo centrará su objeto de estudio concretamente en el caso colombiano y más precisamente en la pena capital como castigo para los delitos graves y atroces cometidos contra los menores de edad. Toda vez que el ordenamiento jurídico colombiano prohíbe expresamente la pena capital, el presente será un análisis meramente teórico-filosófico del asunto, tomando como punto de partida la delimitación de conceptos clave como los son justicia y libertad. No es la pretensión última de este precario ensayo llegar a justificar la pena de muerte como medida coercitiva definitiva, tampoco afirmar categóricamente que sea este el castigo idóneo para la disminución de los delitos graves y atroces en contra de

* Artículo producto del proyecto de investigación: "Pena de muerte en Colombia”, desarrollado en la cátedra Teoría del Derecho, bajo la dirección de la docente Estefanía Acosta Páez de la Universidad Católica de Colombia. Citar como: Rojas Martínez, F. A. (2019). Pena de muerte en Colombia, una medida no tan extrema a la luz del iusnaturalismo. Revista IUSTA, 1(50), 193-210. DOI: https://doi. org/10.15332/1900-0448.2019.0050.08

** Estudiante del Programa de Derecho de la Universidad Católica de Colombia. Correo electrónico: farojas86@ucatolica.edu.co - ORCID: 0000-0003-4597-2690. 
menores, no solo en Colombia, sino en la mayoría de países. Es más bien una postura crítica hacia la degradación de la sociedad colombiana y la indiferencia y casi olvido por parte del Estado hacia los sectores más vulnerables de la misma, viéndose reflejado esto último en la ausencia de mecanismos que puedan hacer efectivas las ordenanzas que protegen a los menores.

Palabras clave: pena de muerte, estado liberal, democracia, principios fundamentales, derechos fundamentales, derecho internacional humanitario.

\title{
Death penalty in Colombia, a not so extreme MEASURE IN THE LIGHT OF NATURAL LAW
}

\begin{abstract}
A similar subject of discussion is not easy to address, since it goes back to the origins of civilization itself. From the legal point of view, it is a confrontation between two basic fundamental principles of any Western normative system, that is, between the principle of Freedom and the principle of Justice, which are immersed and omnipresent in the very essence of law. Although legal science seems to be responsible for deciding whether it is justifiable to take someone's life, deep discussion involves fields of knowledge ranging from religion to the natural sciences, and reaches the orbit of other difficult legal issues such as abortion and euthanasia. However, the analysis that is intended to be carried out in this essay will center its object of study, specifically in the Colombian case and more precisely, in capital punishment as punishment for serious and atrocious crimes committed against minors. Since the Colombian legal system expressly prohibits capital punishment, the present will be a purely theoretical-philosophical analysis of the matter, taking as a starting point the delimitation of key concepts, such as justice and freedom. It is not the ultimate pretense of this precarious trial to justify the death penalty as a final coercive measure, nor to state categorically that this is the appropriate punishment for the reduction of serious and atrocious crimes against minors, not only in Colombia, but also in Colombia. Most countries. It is rather a critical position towards the degradation of Colombian society, and the indifference and almost forgetfulness on the part of the State towards the most vulnerable sectors of it, this being reflected in the absence of mechanisms that can make effective the ordinances that protect to the minors.
\end{abstract}


Keywords: death penalty, liberal state, democracy, fundamental principles, fundamental rights, international humanitarian law.

\section{Pena de morte na Colômbia, uma medida NÃO TÃO EXTREMA À LUZ DA LEI NATURAL}

\section{Resumo}

Um assunto semelhante de discussão não é fácil de abordar, uma vez que remonta às origens da própria civilização. De um ponto de vista legal, é um choque entre dois princípios fundamentais básicos de qualquer sistema jurídico ocidental, isto é, entre o princípio da liberdade e o princípio da justiça, que são incorporados e onipresente na própria essência do direito. Enquanto a ciência jurídica parece ser responsável por decidir se é justificável a tirar a vida de alguém, profunda discussão envolve áreas do conhecimento que vão desde a religião à ciência natural, e atinge a órbita de outras questões legais difíceis como o aborto ea eutanásia No entanto, a análise que se pretende realizar neste ensaio centrará seu objeto de estudo, especificamente no caso colombiano e mais precisamente, na pena capital como punição por crimes graves e atrozes cometidos contra menores. Como o sistema legal colombiano proíbe expressamente a pena de morte, o presente será uma análise puramente teórico-filosófica do assunto, tomando como ponto de partida a delimitação de conceitos-chave, como a justiça e a liberdade. Não é o objetivo final deste julgamento precária mesmo justificar a pena de morte como medida de coacção final, não declarar categoricamente que esta é a punição adequada para a redução de crimes graves e hediondos contra crianças, não só na Colômbia, mas em A maioria dos países. É, antes, uma postura crítica em relação à degradação da sociedade colombiana, e indiferença e quase esquecido pelo Estado para os setores mais vulneráveis da mesma, vendo-se refletido o último, na ausência de mecanismos para fazer cumprir preceitos que protegem para os menores.

Palavras-chave: pena de morte, estado liberal, democracia, princípios fundamentais, direitos fundamentais, direito internacional humanitário. 


\section{Introducción}

Los profundos cambios en materias políticas, sociales y económicas experimentados a nivel mundial en los últimos años, han acrecentado una gran diversidad de intereses, actores y escenarios de discusión (Blanco, 2011). La humanidad ha venido experimentando enormes cambios a nivel social, político, económico, tecnológico y científico durante los últimos veinte años. Estos cambios surgen de las ruinas del siglo XX, en el cual se dieron guerras mundiales y trajeron increíbles avances tecnológicos que hoy nos parecen cotidianos. Con los horrores de las guerras y la posibilidad aún latente y real de un exterminio a escala global de la Guerra Fría, las últimas generaciones han cultivado una consciencia de protección de la vida y los derechos y libertades individuales, marcada políticamente por las teorías del Estado liberal y principios democráticos entendidos como necesarios a raíz de los niveles de maldad que somos capaces de alcanzar independientemente de su motivación (Umbarila, 2018).

En el caso del conflicto armado en Colombia, cuyo origen se cuenta oficialmente desde la creación de las Farc, este deja una cifra contabilizada hasta el año 2017 de 8074272 víctimas, de las cuales 7134646 son casos de desplazamiento, 983033 homicidios, 165927 desapariciones forzadas, 10237 torturas y 34814 secuestros, entre otros hechos, según cifras del Registro Único de Victimas (RUV).

Sin embargo, este conflicto tiene orígenes que se remontan mucho más allá de los años sesenta del siglo anterior, por lo tanto, es muy difícil determinar cifras que se acerquen a la realidad. Pero más grave aún es el hecho de que el conflicto alcanzó puntos de degradación sin precedentes en cuanto a los vejámenes a que fueron sometidos no solo actores directos del conflicto, sino también involucrando civiles en estado de indefensión, entre ellos muchos menores de edad, todo esto materializado en los métodos utilizados por grupos paramilitares que justificaban su accionar en la lucha antisubversiva; así mismo, en la ofensiva guerrillera que trajo consigo la vulneración de derechos en contra de la sociedad civil y la corrupción de sectores políticos, la rama judicial y de la sociedad civil en general, todo esto alimentado con enormes cantidades de dinero generadas con base en el narcotráfico.

La complejidad de la guerra civil en Colombia hace que sea así mismo complejo su estudio. De vieja data es la polarización de nuestra sociedad y sus orígenes se rastrean a los tiempos de la Independencia misma, período conocido como "la patria boba", con causas tales como la injusticia social, abandono del Estado, 
tierras y desigualdad, que a su vez, han servido de combustible para avivar el conflicto en comento.

Esta degradación se dio a conocer a través de testimonios entregados por las víctimas, desde la desmovilización de grupos paramilitares durante el Gobierno de Álvaro Uribe Vélez, en los cuales se relata el horror que tuvieron que vivir en Colombia durante largos años habitantes de regiones apartadas de nuestra nación, con un especial abuso hacia menores quienes sufrieron violaciones, torturas, asesinatos, desapariciones, reclutamiento forzado, agravado por los métodos utilizados para tales fines. Están aún por verse las cifras que dejará la JEP cuando se haga pública la "verdad" de los acuerdos de paz con las Farc.

Lo anterior parece justificado en el marco de un conflicto tan prolongado como lo es el colombiano, sin embargo, es evidente la vulneración de derechos humanos y del derecho internacional humanitario, una vez se reconoció la existencia del conflicto interno en nuestro país.

Esta larga tradición violenta y de división se ha incorporado de tal forma en nuestra idiosincrasia, alcanzando un punto superlativo en la última década del siglo pasado, época en la cual el conflicto entre grupos de ultraderecha, Estado, guerrillas y narcotraficantes escaló hasta superar todos los límites de barbarie conocidos hasta entonces para con nuestros coterráneos, y cuyas víctimas fueron principalmente indígenas, afrocolombianos y en general los sectores más vulnerables de la sociedad.

Huelga decir que los menores fueron victimizados por esta escalada violenta según los precitados delitos, lo cual trajo como consecuencia positiva la creación de la Ley 1098 de 2006, Código de Infancia y Adolescencia, cuya finalidad es,

\section{[...] garantizar a los niños, a las niñas y a los adolescentes su pleno y armonioso de- sarrollo para que crezcan en el seno de la familia y de la comunidad, en un ambiente de felicidad, amor y comprensión. Prevalecerá el reconocimiento a la igualdad y la dignidad humana, sin discriminación alguna.}

En este sentido, tenemos que los derechos de los menores en Colombia se encuentran amparados, desde el ámbito internacional, en cartas como la Declaración de los Derechos del Niño y la Convención sobre los Derechos del Niño, y en calidad de civiles por el derecho de los derechos humanos y el derecho internacional humanitario, en la Constitución de 1991 en su artículo 44 y en la ya mencionada Ley 1098 de 2006. 
Como bien puede evidenciarse, el problema no es la ausencia de manifestación de derechos de la niñez ya que los mismos se encuentran garantizados expresamente en nuestro ordenamiento positivo, entonces, ¿por qué no existen mecanismos que permitan su eficacia y hacer valer su fuerza vinculante?, ¿acaso la consecuencia jurídica que trae consigo la inobservancia de tales ordenanzas no es lo suficientemente coercitiva?

Un castigo que sea ejemplarizante, un sistema jurídico que funcione efectivamente sin intereses políticos ni económicos, que no se encuentre permeado por la corrupción, y una sociedad que necesita con urgencia la reconciliación y una reestructuración moral como una herramienta complementaria al derecho positivo, se configuran como presupuestos necesarios para la construcción de un camino hacia una paz duradera, que permita un ambiente sano para el desarrollo de nuestros niños y un país en el cual se vea reducida a su mínima expresión la vulneración de sus derechos fundamentales. Al respecto y de conformidad con Osorio (2018),

[...] la extradición es la figura jurídica judicial de mayor expresión en materia de cooperación internacional; siendo los casos más notorios de procedencia, el terrorismo, narcotráfico, blanqueo de capitales, armas, trata de personas, organizaciones criminales y demás conductas punibles conexas a los anteriores, así como los delitos contenidos en el Estatuto de Roma. Esta figura cooperativa en algunos estamentos ha superado una serie de barreras de conveniencia política, económicas, jurídicas y sociales, convirtiéndose en una institución más viable y de mayor validez, pues ha pasado de ser una política de gobierno a ser una política estatal, además de ampliar su espectro de aplicabilidad, pasándose de la simple remisión de criminales a la reciprocidad de información, investigación, asistencia judicial, entre otros (p. 179).

En concordancia con lo dispuesto en líneas anteriores y de conformidad con Huertas, Rumbo y Uribe (2018), es necesario resaltar que

[...] si bien la cárcel es la pena más antigua y opresora que ha sido implementada en el mundo, infortunadamente aún no existe una pena que pueda reemplazar el ejercicio y función de esta, son los jueces de vigilancia penitenciaria los que en exclusiva hacen ejecutar lo juzgado en ejercicio de la potestad jurisdiccional, y con ello cumplen no solo con el mandamiento judicial determinado en una sentencia, sino también cumplen con lo consagrado en el mandato constitucional y se convierte 
en automático en un ente garante de los derechos de las personas privadas de la libertad, teniendo la gran labor de reivindicar la función jurídico-estatal de las instituciones penitenciarias (p. 74).

\section{La necesidad de vivir en paz, un derecho y un deber}

La Constitución de 1991 se caracteriza por garantizar derechos fundamentales, característica de los Estados sociales de derecho modernos, cuyo principio rector es la democracia y la participación democrática (Guarín, Rosse y Robayo, 2018).

Allí se determina categóricamente en su artículo 22: "La paz es un derecho y un deber de obligatorio cumplimiento”, para cuya consecución el Estado colombiano ha intentado pacificar el país por medio del uso y el abuso de la fuerza, lo que trajo como consecuencia un baño de sangre que en nada contribuyó a hacer realidad lo ordenado por el artículo superior; por el contrario, generó más violencia y sacrificó principios de justicia, equidad e integridad que se vieron menoscabados por el mismo Estado, bien sea por acción u omisión en sus políticas antisubversivas. Así mismo, este conflicto, su escalada violenta y su degradación, crearon un marco que permitió a sus actores llevar a cabo prácticas de guerra en franca contravención de la Carta Constitucional, cuando en su artículo 12 ordena expresamente que: "Nadie será sometido a desaparición forzada, a torturas ni a tratos o penas crueles, inhumanos o degradantes", y sigue en su artículo 13:

Todas las personas nacen libres e iguales ante la ley, recibirán la misma protección y trato de las autoridades y gozarán de los mismos derechos, libertades y oportunidades sin ninguna discriminación por razones de sexo, raza, origen nacional o familiar, lengua, religión, opinión política o filosófica. El Estado promoverá las condiciones para que la igualdad sea real y efectiva y adoptará medidas en favor de grupos discriminados o marginados. E1 Estado protegerá especialmente a aquellas personas que por su condición económica, física o mental, se encuentren en circunstancia de debilidad manifiesta y sancionará los abusos o maltratos que contra ellas se cometan.

Por lo anterior, en un análisis sistemático de la Carta Política, la paz como deber de obligatorio cumplimiento no puede ser una excusa para justificar los crímenes 
que en su procura se cometan, más aun, en contra de menores, quienes gozan de especial protección constitucional y legal en nuestro país. Viene al caso recordar el artículo 44 superior según el cual:

Son derechos fundamentales de los niños: la vida, la integridad física, la salud y la seguridad social, la alimentación equilibrada, su nombre y nacionalidad, tener una familia y no ser separados de ella, el cuidado y amor, la educación y la cultura, la recreación y la libre expresión de su opinión. Serán protegidos contra toda forma de abandono, violencia física o moral, secuestro, venta, abuso sexual, explotación laboral o económica y trabajos riesgosos. Gozarán también de los demás derechos consagrados en la Constitución, en las leyes y en los tratados internacionales ratificados por Colombia. La familia, la sociedad y el Estado tienen la obligación de asistir y proteger al niño para garantizar su desarrollo armónico e integral y el ejercicio pleno de sus derechos. Cualquier persona puede exigir de la autoridad competente su cumplimiento y la sanción de los infractores. Los derechos de los niños prevalecen sobre los derechos de los demás (subrayado no pertenece al texto original).

$\mathrm{Al}$ respecto, y como comentario a tener en cuenta en el marco de las relaciones internacionales, es preciso anotar que luego de la celebración de los variados tratados internacionales pareciera que Colombia debería buscar puntos focales regulatorios de ciertos temas (Castro, 2018).

Es así entonces que no es solamente el Estado colombiano, sino también la sociedad y la familia quienes deben garantizar que se protejan y hagan efectivos los derechos de los niños, aunque como se señaló anteriormente, esto no ha sido así en nuestro país. Resultan particularmente escalofriantes los relatos de las víctimas de los paramilitares en los que se habla de decapitaciones, violaciones, abusos de inimaginable crueldad, sin que haya existido un castigo para sus victimarios que incluya justicia reparativa y una sanción ejemplarizante que persuada a quienes pretendan cometer vejámenes similares; en consecuencia, el mismo riesgo de cuasiimpunidad se corre con la desmovilización de las Farc, de quienes se sabe que algunos de sus miembros prostituían niñas, reclutaban forzosamente para sus filas a menores secuestrados y alejados de sus familias. Todo esto en claras violaciones a derechos fundamentales, crímenes que al parecer van a quedar en la impunidad con motivo de la búsqueda de la tan anhelada paz en nuestro territorio nacional. 
Si bien es cierto que las mujeres, indígenas, campesinos y afrodescendientes, entre otros importantes sectores que conforman la sociedad colombiana, han sido igualmente victimizados, el presente ensayo se centrará en los menores. Por lo anteriormente dicho, ya estos gozan de una especial protección constitucional y por ordenanzas internacionales que Colombia ha suscrito y ratificado.

El objeto de estudio que aquí nos atañe ha trascendido escenarios naturales de enfrentamientos directos entre actores del conflicto armado colombiano, con lo que tenemos que la violencia inhumana y consiguiente vulneración de derechos humanos y fundamentales a la que se vieron sometidos muchos de nuestros niños, no es exclusiva del contexto del conflicto armado y de zonas rurales y apartadas de nuestro territorio; este hecho se hizo evidente y más aún, fue motivo de exposición mediática en la capital colombiana a raíz del famoso caso de violación, tortura y asesinato, cuya víctima fue una niña de 7 años. Yuliana Samboní fue víctima de Rafael Uribe Noguera, arquitecto bogotano de familia acomodada, quien la secuestró, violó, torturó, asesinó y además intentó desaparecer el cuerpo, por lo cual fue condenado a 51 años de cárcel (condena aumentada posteriormente a 58 años).

Lo preocupante del caso es que pueda ser la punta del iceberg de una estructura más grande, de una sociedad enferma, y más preocupante aún, de un sistema jurídico ineficaz, incapaz de persuadir de estos comportamientos a los criminales en potencia y que prevé como máxima condena 60 años de prisión para este tipo de ilícitos, solo después de determinar agravantes como el feminicidio.

En ese mismo sentido, los mecanismos para la aplicación de la ley son lentos e ineficientes, quedando muchas veces casos de igual gravedad como el de Yuliana en la más oscura impunidad, toda vez que, al no ser mediáticos, no reciben la importancia y atención que deberían.

En concordancia con las líneas planteadas es importante no olvidar que,

[...] las transformaciones de la teoría del derecho de forma reciente, por factores como la amplia producción teórica en los Estados considerados centrales o la llegada de conceptos, interpretaciones de la realidad y corrientes teóricas de contextos académicos que fueron considerados marginales, determina un horizonte de deliberaciones teóricas que tienen la pretensión de comprender fenómenos contemporáneos donde las ciencias sociales, las especialidades de la ciencia jurídica y la misma teoría del derecho son esenciales (Llano, Rengifo y Rojas 2017, p. 31). 


\section{Problema jurídico}

Ante situaciones como estas, existen varios factores que se deben tomar en cuenta al momento de determinar cuál debería ser el castigo adecuado, que contenga elementos de persuasión, prevención, justicia y retribución a la vez. Esto es, que además de que repare a la víctima o a su familia, sea capaz de persuadir y prevenir que se repita no solo por el victimario, sino también de potenciales replicantes del mismo delito; además que se encuentre en consonancia sistemática con principios de justicia, equidad y libertad. Así pues, la pena capital para delitos atroces contra menores se perfila como una opción que puede cumplir con los anteriores presupuestos y que además, puede contribuir a que la sociedad sienta que se aplica justicia ya que se garantiza la no repetición. Esto por supuesto plantea problemas y conflictos que deberán analizarse a la luz de nuestra Constitución en donde se ampara el derecho a la vida teniendo en cuenta principios generales del derecho. Tenemos entonces que ponderar principios, normas constitucionales y derechos de los niños para determinar si la pena capital para delitos atroces contra menores tiene alguna posibilidad teórica de incluirse en el ordenamiento jurídico colombiano. Para ello es necesario aclarar que la pena de muerte se encuentra prohibida en Colombia, por lo tanto, la presente es una reflexión hipotética de carácter meramente teórico-filosófica.

\section{De la pena capital en Colombia}

En el caso colombiano, la pena de muerte fue abolida definitivamente en 1910 mediante acto legislativo n. ${ }^{\circ} 3$ en su título (III), artículo 3, según el cual: "En el nombre de Dios, fuente suprema de toda autoridad, la Asamblea Nacional Colombiana decreta: [...] El legislador no podrá imponer la pena capital en ningún caso", siendo la última ejecución registrada en 1909.

Muchos años después, la Constitución de 1991 fundamentada en principios diferentes y teniendo como soberano al pueblo, en su artículo 11, capítulo (I), sobre derechos fundamentales, promulga que: "El derecho a la vida es inviolable. No habrá pena de muerte".

Así las cosas, en 1997 fue presentado un proyecto de ley para restaurar la pena capital, pero la propuesta fue rechazada, pues Colombia ratifica el "Segundo Protocolo Facultativo del Pacto Internacional de Derechos Civiles y Políticos, 
destinado a abolir la pena de muerte", y posteriormente en 2010, el presidente Juan Manuel Santos Calderón, promulgó la Ley 1410 de 2010, por la que se aprueba el "Protocolo a la Convención Americana sobre Derechos Humanos Relativos a la Abolición de la Pena de Muerte". Todo esto ratificado por la Corte Constitucional mediante las Sentencias C-144/97 y C-399/11.

En esto Colombia se encuentra en la línea de los Estados modernos que no admiten la ley del talión, porque se considera la pena de muerte como una venganza encubierta que va en contra del derecho a la vida, que es en nuestro ordenamiento, un derecho fundamental. Según el criterio que se elija, se deben tener en cuenta también a las víctimas y a las posibles víctimas de los mismos delitos si no se aplica un castigo ejemplar, esto es, si la víctima o sus familiares tienen posibilidad de algún tipo de reparación, con lo cual se haría necesario que esta se diera antes de aplicar la pena de muerte, o si es claro que puede existir el escenario para una revictimización o la imposibilidad de resarcir el daño hecho por algún medio por parte del victimario, lo único que queda es aplicar justicia retributiva.

\section{Posición del naturalismo frente a la pena capital}

La Iglesia católica y el derecho canónico se han mostrado en contra de una pena irreversible como la capital, por considerarla como una mera venganza que en nada aporta a una eventual resocialización del delincuente.

Así mismo, Beccaria en su libro De los delitos y las penas (1764), se enfrentó a la pena de muerte argumentando que este castigo tiene una función exclusivamente intimidatoria. "La finalidad (de la pena) no es otra que la de impedir al reo causar más daños a sus conciudadanos y apartar a otros de obrar igualmente".

Sin embargo, Santo Tomás de Aquino en su máxima obra Summa teológica (parte II, cap. 2, párrafo 64) y tomando como base argumentativa sus convicciones religiosas que difícilmente pueden esgrimirse en ordenamientos jurídicos modernos como el nuestro, sostiene que:

[...] todo poder correctivo y sancionario proviene de Dios, quien lo delega a la sociedad de hombres; por lo cual el poder público está facultado como representante divino, para imponer toda clase de sanciones jurídicas debidamente instituidas con el objeto de defender la salud de la sociedad. De la misma manera que es conveniente y lícito amputar un miembro putrefacto para salvar la salud del resto del 
cuerpo, de la misma manera lo es también eliminar al criminal pervertido mediante la pena de muerte para salvar al resto de la sociedad.

Un filósofo muy influyente y moderno que siempre ha de tomarse en cuenta en discusiones morales en la órbita del iusnaturalismo, es sin duda alguna Immanuel Kant, quien partiendo del concepto retributivo de la pena, según el cual la función de la pena no es la de prevenir los delitos, sino puramente hacer justicia, es decir, hacer que haya una perfecta correspondencia entre el delito y el castigo, siendo esta una plena justificación para la aplicación de la pena capital para determinados delitos. Se trata de la justicia como igualdad, que los antiguos llamaban "igualdad correctiva”, así mismo sostiene que el deber de la pena de muerte corresponde al Estado y es un imperativo categórico, no un imperativo hipotético, basado en la relación medio-finalidad.

En este punto introducimos un alcance al concepto de justicia, el carácter retributivo de la misma que se apoya en la regla de la justicia como igualdad. Al igual que Kant, Hegel (Filosofía del derecho, 1821/1968) defiende la correspondencia entre iguales, según la máxima de justicia retributiva la cual determina que es justo que quien ha cometido una acción malvada sea objeto del mismo mal que ha ocasionado a otros y, por lo tanto, es justo que quien mata sea muerto; así también tal castigo incorpora el concepto preventivo según el cual la función de la pena es desalentar, con la amenaza de un mal, las acciones que determinado ordenamiento considera perjudiciales. Tomando en cuenta los anteriores elementos, la pena de muerte solo está justificada si se puede demostrar que su fuerza intimidadora es grande y superior a la de cualquier otra pena o sanción.

Para fundamentar filosóficamente el desestimar la vida del criminal, regresamos a Kant, quien considera que en la comisión de un delito el criminal decidió regresar al estado de naturaleza, a un estado en el que nadie tiene derecho alguno y la libertad (externa) es continuamente amenazada mientras que el imperativo categórico nos exige protegerla. El criminal acepta la desaparición de la libertad externa de su propia voluntad. Lo anterior significa que la voluntad del criminal se elimina al momento en que decide cometer el ilícito, con lo cual deja de ser ciudadano y en consecuencia el amparo de sus derechos fundamentales ya no es vinculante. 


\section{Alcance del concepto de justicia. Principios enfrentados}

Según hemos visto, el concepto de justicia es muy difuso y existen muchas variantes a las cuales se puede acudir; sin embargo, la que aquí se va a tener en cuenta es la justicia a la que hacen referencia Kant y Hegel, a la justicia retributiva.

Si bien es cierto que para el caso colombiano se han creado marcos de justicia especial en los cuales se ignoran delitos considerados de lesa humanidad y delitos atroces para desmarcarse de tratados internacionales que harían imposibles procesos de paz y desmovilización de grupos armados al margen de la ley; estos permiten una justicia transicional necesaria para generar condiciones aceptables por los actores del conflicto que han cometido estos delitos pero que desean reincorporarse a la sociedad civil.

Difícil y particular situación histórica la de Colombia, sin embargo, es necesario sacrificar justicia con el fin de conseguir un bien superior que en este caso es la paz.

Empero, lo anterior no quiere decir que esto deba ser así para quienes por fuera del marco del conflicto armado han cometido y siguen cometiendo este tipo de delitos, como en el caso de Rafael Noguera o el terrible caso de Rosa Elvira Cely, en el cual el criminal ya había sido condenado por el mismo delito y sin embargo se encontraba en libertad, la cual aprovechó para cometer este abominable crimen.

\section{Principios generales del derecho enfrentados}

\section{De la libertad}

$\mathrm{Al}$ igual que la justicia, la libertad es un principio rector que se ve reflejado en nuestra Constitución. Esto quiere decir que tienen el mismo rango constitucional además de tener carácter de principios a los cuales se les da preponderancia sin duda, como se puede ver en el artículo 28 superior:

Toda persona es libre. Nadie puede ser molestado en su persona o familia, ni reducido a prisión o arresto, ni detenido, ni su domicilio registrado, sino en virtud de mandamiento escrito de autoridad judicial competente, con las formalidades legales y por motivo previamente definido en la ley [...]. 
La libertad considerada en una posible incorporación de la pena capital en nuestro ordenamiento jurídico, es fundamental ya que se trata de decidir qué castigo sería más severo, la privación de la libertad o la privación de la vida, cuál de estos es más persuasivo y más efectivo en la prevención de la reincidencia del delincuente en el mismo delito, cuál de las dos alternativas es más conveniente para la sociedad.

\section{El respeto a la vida}

La vida en Colombia es sagrada según ya hemos visto anteriormente. Este concepto ambiguo, en el sentido de que se trata de una regla positiva justificada en lo sagrado, no ha sido observada como puede constatarse en el pequeño recuento histórico del conflicto colombiano. Sin embargo, es un deber estatal y de la sociedad colombiana velar por que así sea, más aun cuando se trata de menores, que como ya también se vio, están especialmente protegidos por nuestro ordenamiento jurídico.

Este es el principal argumento en contra de la pena capital, un argumento sin duda de la mayor preponderancia, ya que sería a todas luces contrario a la Constitución instaurar la pena de muerte como castigo aun cuando sea para delitos atroces contra menores.

\section{Ponderación de principios}

Así pues, desde el punto de vista kantiano, la justicia retributiva puede aplicarse perfectamente justificada en la perdida de voluntad del criminal, por consiguiente, este ya no se encuentra vinculado a la Constitución; en tal sentido ya no tendría derechos fundamentales que se puedan amparar en su favor. No así su deber de responder retributivamente frente al Estado y la sociedad.

Por otra parte existe un factor económico, no solo monetario, también en el sentido jurídico, como bien lo expone Gary Becker en su ensayo sobre la economía del delito, Crimen y castigo: un enfoque económico: "La anticipación de la condena y el castigo reduce la pérdida de los delitos y, por lo tanto, aumenta el bienestar social al desalentar a algunos delincuentes”.

Dicha anticipación la justifica el autor argumentando que el criminal le teme más a la certeza de que será atrapado y enjuiciado que a la severidad del castigo, que en este caso sería la muerte, empero, sí existe la posibilidad latente de perder 
la vida como consecuencia de su encarcelamiento, sería más persuasivo en cuanto a prevenir la comisión del delito y más económico para el sistema judicial evitando procesos largos y tediosos; para el Estado también representa un beneficio económico ya que no tendrá que mantener un reo durante 60 años (la pena máxima en Colombia para estos delitos).

Ahora bien, se trata de ponderar principios a los cuales debemos remitirnos para decidir cuál tiene más peso en la decisión según lo explica Dworkin en su libro Los derechos en serio, es decir, considerar su esencia y las posibles consecuencias de su aplicación, cuál es más aplicable para el caso. Robert Alexy señala que la Ley de Ponderación puede sintetizarse en la siguiente regla: "cuanto mayor sea el grado de no satisfacción o restricción de un principio, tanto mayor tiene que ser la importancia de la satisfacción del otro", lo cual quiere decir que se debe dar más peso al que mayor grado de satisfacción respecto al enfrentado proporcione a la solución de una controversia, en este caso cuál trae mayor beneficio en su aplicación.

En este sentido, la ponderación no resiste análisis, claramente la pena de muerte queda justificada cuando la naturaleza del delito es un crimen atroz contra un menor de edad; la experiencia ha demostrado que estos delincuentes no tienen posibilidad de resocialización y la única alternativa es una pena de 60 años, durante los cuales se deberán invertir recursos en su manutención con la posibilidad latente de que saldrán en libertad en un futuro sin que se tenga certeza de que no repetirán los delitos que los llevaron a perder su libertad la primera vez.

\section{Garantías constitucionales}

\section{El debido proceso y la presunción de inocencia}

Nuestra Constitución contiene varias garantías constitucionales, una de las cuales es la consagrada en el artículo 29, esto es el "debido proceso":

El debido proceso se aplicará a toda clase de actuaciones judiciales y administrativas. Nadie podrá ser juzgado sino conforme a leyes preexistentes al acto que se le imputa, ante juez o tribunal competente y con observancia de la plenitud de las formas propias de cada juicio. En materia penal, la ley permisiva o favorable, aun cuando sea posterior, se aplicará de preferencia a la restrictiva o desfavorable. Toda persona se presume inocente mientras no se la haya declarado judicialmente 
culpable. Quien sea sindicado tiene derecho a la defensa y a la asistencia de un abogado escogido por él, o de oficio, durante la investigación y el juzgamiento; a un debido proceso público sin dilaciones injustificadas; a presentar pruebas y a controvertir las que se alleguen en su contra; a impugnar la sentencia condenatoria, y a no ser juzgado dos veces por el mismo hecho. Es nula, de pleno derecho, la prueba obtenida con violación del debido proceso.

En una eventual incorporación de la pena de muerte para delitos atroces contra menores, la garantía al debido proceso debe estar respaldada por un sistema infalible de justicia en el que se pruebe más allá de cualquier duda razonable, de modo que no sea posible condenar a un inocente; esto sin dudas es una fantasía ya que la infalibilidad no es una característica de ningún sistema penal. La implementación de una pena tan severa requiere también garantías y mecanismos más estrictos para evitar ir en contra del principio rector del derecho, la justicia. Así como el debido proceso, es también fundamental fortalecer las demás garantías constitucionales, en el caso penal, la presunción de inocencia. Ferrajoli en su texto Derecho y razón: teoría del garantismo penal (1989), plantea la necesidad de una democracia sustancial protectora de los derechos y libertades sociales de los individuos, para lo cual se requieren tres elementos: a) un órgano legítimo que organice a las naciones, b) la promoción de la paz y, c) una jurisdicción penal internacional, con el fin de generar garantías constitucionales que nos direccionen hacia la paz. Según Ferrajoli, la manera de otorgar garantías efectivas es la subordinación política al derecho, que es lo único que puede limitar el poder y evitar abusos.

\section{Conclusiones}

La línea argumentativa seguida hasta aquí, nos trae irremediablemente a la conclusión de que no solamente en Colombia sino también en la mayoría de democracias occidentales es impensable permitir la pena de muerte como castigo. Como vimos, el iusnaturalismo considera justificable su aplicación como medio para alcanzar justicia retributiva. La posibilidad de que delitos atroces contra menores queden en la impunidad es latente, y al no existir mecanismos y castigos que permitan disuadir a potenciales criminales, esto es, enfocados a prevenir y proteger a los menores haciendo valer sus derechos constitucionales fundamentales, parece que no existe una alterativa plausible que nos proporcione 
la posibilidad de una sociedad reconciliada y en paz, para lo cual es indispensable que exista una justicia eficaz.

Probablemente se deba empezar a pensar en una democracia internacional, como propone el filósofo florentino, lo cual facilitaría una jurisdicción penal internacional que pueda ejercer un mejor y más eficaz control en procesos de juzgamiento de este tipo de delitos, hacer efectivas las garantías constitucionales y fortalecer instituciones nacionales que permitan la plena eficacia en la aplicación de la ley.

\section{Referencias}

Alexy, R. (2010). La construcción de los derechos fundamentales. Buenos Aires, Argentina. Ad-Hoc.

Aquino, T. (1964). Suma Teológica I: Madrid, España: Biblioteca de Autores Cristianos. Beccaria, L. (1764/2006). De los delitos y las penas. Bogotá D. C., Colombia: Temis.

Becker, G. (1974). Crimen y castigo: un enfoque económico. México D. F., México: NBER.

Blanco, C. (2011). La importancia social y política del Parlamento Andino. Revista Via Inveniendi et Iudicandi, 6(1). Recuperado de http://revistas.usantotomas.edu.co/index. $\mathrm{php} /$ viei/article/view/2941/2813

Bobbio, N. (2001). No matarás. Barcelona, España: Península.

Castro, G. (2018). Una nueva propiedad intelectual para el siglo XXI. Focos, críticas y propuestas puntuales para una futura regulación de los bienes inmateriales. Revista IUSTA, 1(48), 19-41. DOI: https://doi.org/10.15332/s1900-0448.2018.0048.01. Recuperado de http://revistas.usta.edu.co/index.php/iusta/article/view/4085/3880

Constitución Política colombiana. (1991). Asamblea Nacional Constituyente, Bogotá D. C., Colombia, 6 de julio de 1991.

Dworkin, R. (1984). Los derechos en serio. Barcelona, España: Editorial Ariel, S. A.

Ferrajoli, L. (1995). Derecho y razón. Teoría del garantismo penal. Madrid, España: Ttrotta

Guarín Ramírez, E. A., Rosse Calderón, R., y Robayo, A. (2018). Incidencia de los medios de comunicación en la administración de justicia en Colombia. Revista Verba Iuris, 13(40), 83-94.

Hegel, G. W. F. (1821/1968). Filosofía del derecho. Buenos Aires, Argentina: Editorial Claridad S. A.

Hegel, G.W. F. (1975). Introducción a la historia de la filosofia. Madrid, España: Aguilar.

Huertas, O., Rumbo, C., y Uribe, A. (2018). El juez de vigilancia penitenciaria en España, como referente de la ejecución penal en América Latina. Revista IUSTA, 1(48) 73-96. 
DOI: https://doi.org/10.15332/s1900-0448.2018.0048.03. Recuperado de http:// revistas.usta.edu.co/index.php/iusta/article/view/4087/3882

Kant, I. (1989). La metafísica de las costumbres. Madrid, España: Tecnos.

Ley 1098. (2006). Código de Infancia y Adolescencia. Diario Oficial n. ${ }^{\circ} 46.446$ de la República de Colombia, Bogotá D. C., Colombia, 8 de noviembre de 2006.

Llano, V., Rengifo, R., y Rojas, L. (2018). Estado cosmopolita en América Latina. Revista IUSTA, 1(48), 97-117. DOI: https://doi.org/10.15332/s1900-0448.2018.0048.04. Recuperado de http://revistas.usta.edu.co/index.php/iusta/article/view/4088/3883

Osorio, R. (2018). La extradición y la cooperación internacional. Falta de justicia, legitimidad o incapacidad del Estado colombiano: su historia. Revista IUSTA, 1(48), 179-198. DOI: https://doi.org/10.15332/s1900-0448.2018.0048.07. Recuperado de http:// revistas.usta.edu.co/index.php/iusta/article/view/4097/3904

Umbarila Rodríguez, J. I. (2018). Naturaleza e ineficacia institucional en la América española. Revista Verba Iuris, 13(40), 149-174. 